\section{What is already known on this topic}

Seasonal allergic rhinitis (hay fever) is common in countries with temperate climates.

Most patients have their symptoms treated for short periods, particularly during peaks in atmospheric pollen count

\section{What this study adds}

After two weeks, the effects of butterbur and cetirizine were comparable in patients with hay fever

Butterbur produced fewer sedating effects than cetirizine

Butterbur should be considered when the sedating effects of antihistamines must be avoided

\section{Value of butterbur}

Although the effects of butterbur have been linked to its constituents, ${ }^{5-7}$ we set out to test whether its clinical effects in seasonal allergic rhinitis were comparable to those of antihistamines as judged separately and blindly by patients and their doctors. The results showed that the effects of the two treatments are similar. The trends in favour of butterbur in some measures need to be confirmed in future prospective trials. With regard to safety, butterbur was well tolerated and did not have the sedative effects associated with antihistamines. We believe butterbur should be considered for treating seasonal allergic rhinitis, particularly in cases where the sedative effects of antihistamines need to be avoided.

Contributors: see bmj.com

Funding: Zeller AG (Switzerland) supplied study medication and sponsored the study through the Clinical Research Organ- isation Praxis Klinische Arzneimittelforschung, Pohlheim, Germany. The interpretation of the results was the prerogative of the principal investigator and the study group.

Competing interests: None declared.

1 Berman BA. Allergic rhinitis: mechanisms and management. J Allergy Clin Immunol 1988;81;5;980-4

2 Knapp HR. Reduced allergen-induced nasal congestion and leukotriene synthesis with an orally active 5-lipoxygenase inhibitor. $N$ Engl J Med 1990;323:1745-8.

3 Royal Horticultural Society online science and education. Petasites hybridus. www.rhs.org.uk (accessed 28 November 2001)

4 Meier B, Meier-Liebi M. Drogenmonographie Petasites. In: Hänsel R, Keller K, Rimpler H, Schneider G, eds. Hagers Handbuch der pharmazeutischen Praxis. 5th ed. Berlin: Springer Verlag, 1994:81-105.

5 Brune K, Bickel D, Peskar BA. Gastro-protective effects by extracts of Petasites hybridus: the role of inhibition of peptido-leukotriene synthesis. Planta Med 1993;59:494-6.

6 Bickel D, Roder T, Bestmann HJ, Brune K. Identification and characterization of inhibitors of peptido-leukotriene-synthesis from Petasites hybridus. Planta Med 1994;60:318-22.

7 Thomet OAR, Wiesmann UN, Schapowal A, Bizer C, Simon HU. Role of petasine in the potential anti-inflammatory activity of a plant extract of petasites hybridus. Biochem Pharmacol 2001;61:1041-7.

8 British Medical Association and Royal Pharmaceutical Society of Great Britain. Antihistamines, hyposensitisation, and allergic emergencies. British National Formulary. London: BMA, RPRSGB, 1998.

9 Bousquet J, Bullinger M, Fayol C, Marquis P, Valentin B, Burtin B. Assessment of quality of life in patients with perennial allergic rhinitis with a French version of the SF-36 Health Status Questionnaire. J Allergy Clin Immunol 1994;94:182-8.

10 Bousquet J, Duchateau J, Pignat JC, Fayol C, Marquis P, Mariz S, et al. Improvement of quality of life by treatment with cetirizine in patients with perennial allergic rhinitis as determined by a French version of the SF-36 questionnaire. J Allergy Clin Immunol 1996;98:309-16.

11 National Institute of Mental Health: 028 CGI Clinical global impressions. In: Guy W, ed. ECDEU assessment for psychopharmacology. Rockville, MD NIMH, 1976:217-22

12 Abt K. Descriptive data analysis: a concept between confirmatory and exploratory data analysis. Meth Inform 1987;26:77-88.

13 Wheatley D. LI160, an extract of St John's wort versus amitriptyline in mildly to moderately depressed outpatients-a controlled 6-week clinical trial. Pharmacopsychiatry 1997;30(suppl):77-80.

14 Woelk H. Comparison of St John's wort and imipramine for treating depression: randomised controlled trial. BMJ 2000;321;536-9.

15 Schellenberg R. Treatment for the premenstrual syndrome with agnus castus fruit extract: prospective, randomised, placebo controlled study. BMJ 2001;322:134-7.

(Accepted 13 September 2001)

\title{
Analysis of adherence to peak flow monitoring when recording of data is electronic
}

\author{
Helen K Reddel, Brett G Toelle, Guy B Marks, Sandra I Ware, Christine R Jenkins, Ann J Woolcock
}

Correspondence to: H K Reddel

hkr@mail.med.usyd. edu.au

continued over

BMJ 2002;324:146-7

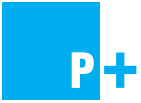

This article is part of the BMJ's randomised controlled trial of open peer review. Documentation relating to the editorial decision making process is available on the BMJ's website
Peak flow monitoring is widely recommended in international asthma guidelines. However, suspicions about the accuracy of conventional pen and paper records were confirmed when studies with electronic spirometers showed poor adherence and falsification of data. ${ }^{1}$ There seems to be a prevailing nihilistic attitude to peak flow monitoring, largely based on the perception that satisfactory adherence cannot be achieved. We aimed to measure long term adherence to electronic peak flow monitoring when participants were aware that data were being stored and used to guide treatment.

\section{Participants, methods, and results}

We obtained data from a 72 week randomised study comparing two starting doses of budesonide in patients aged 18-75 with poorly controlled asthma. The design and outcomes of the study are reported elsewhere. ${ }^{2}$ The study incorporated two novel features: twice daily monitoring with electronic diary spiro- meters (MicroMedical DiaryCard; MicroMedical, Rochester, UK) and titration of dose of budesonide (weeks 17-72) by using a clinical algorithm based on peak flow and diary data. A cumulative chart of peak flow and forced expiratory volume in one second was discussed with each participant at each eight weekly visit. We assessed adherence to monitoring as the percentage of scheduled sessions recorded.

Median overall adherence to monitoring over weeks 1-72 or until withdrawal was $89 \%$ (interquartile range 69-97). Adherence declined gradually from $96 \%$ in weeks $1-8$ to $89 \%$ in weeks $64-72$ (Spearman's $\mathrm{R}=-0.20, \mathrm{P}<0.0001$ for correlation between eight week period and adherence) (figure). Eight participants were withdrawn because of problems with adherence.

\section{Comment}

With appropriate use of electronic devices it is possible to achieve high levels of adherence to monitoring, 


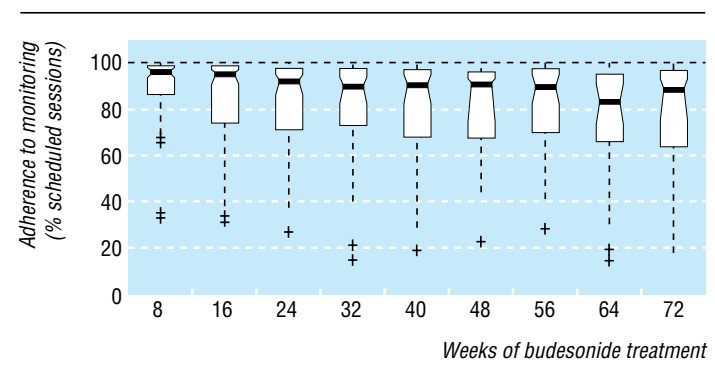

Longitudinal adherence to electronic monitoring over 72 weeks $(n=61)$, calculated as percentage of scheduled sessions performed in each eight week period. Boxes enclose the interquartile range, with the median shown as a thick line and the angled portion of the box indicating the confidence interval of the median. Dashed lines connect observations within 1.5 interquartile ranges of the median. Crosses indicate outliers (more than 1.5 interquartile ranges from the median)

which can be maintained in the long term even when patients have few symptoms. These high levels of adherence are in striking contrast to the findings of studies in which participants, unaware of electronic recording, were also required to complete a pen and paper diary. Verschelden et al found $44 \%$ adherence to monitoring over three months. ${ }^{1}$ However, Chowienczyk et al showed higher adherence over eight weeks for 10 participants using electronic monitoring alone compared with 16 participants who were also required to complete a pen and paper diary (median $91 \% v$ $64 \%, \mathrm{P}<0.05)$.

In consumer marketing, it is axiomatic that non-user friendly design features-whether in mobile phones, internet software, or preprepared meals-will decrease the frequency of use of a product and hence its market share. Similarly, ease of performance of peak flow monitoring could influence adherence to monitoring. Well designed electronic devices substantially ease the burden of monitoring, and this may have been a factor in the high rates of adherence seen in our study and in the short study by Chowienczyk et al.

Additionally, the context in which monitoring is undertaken may influence adherence. In this study, monitoring was used in managing exacerbations by means of a written action plan, and also in adjusting the dose of corticosteroid. These two features are important components of optimal self management education, which has been shown to result in improved outcomes in asthma. ${ }^{4}$ The perceived usefulness to patients of peak flow monitoring may have been enhanced by visual presentation and discussion of data at each visit.

Use of an electronic device ensures collection of accurate, rapidly accessible spirometric data. ${ }^{5}$ This is of little benefit if rates of adherence are low. In the present study, selection of a user friendly electronic device and close integration of this technology into the study design seem to have contributed to adherence rates that challenge current cynicism about the feasibilityand hence the clinical usefulness-of peak flow monitoring. The cost of electronic peak flow devices is currently high, but it may be cost effective to develop cheaper devices, which, by attention to details of design, can also facilitate adherence.

HKR initiated the study of adherence, analysed the data, wrote the manuscript, and with SIW monitored the patients. BGT assisted with interpreting the results and revising the paper. GBM provided statistical advice and analysis. CRJ and AJW (deceased) developed the clinical trial protocol and supervised the study. HKR will act as guarantor.

Funding: AstraZeneca R\&D, Lund, Sweden; AstraZeneca, Ryde, Australia; and National Health and Medical Research Council, Canberra, Australia.

Competing interests: None declared.

1 Verschelden P, Cartier A, L'Archeveque J, Trudeau C, Malo J-L. Compliance with and accuracy of daily self-assessment of peak expiratory flows (PEF) in asthmatic subjects over a three month period. Eur Respir J 1996;9:880-5.

2 Reddel HK, Jenkins CR, Marks GB, Ware SI, Xuan W, Salome CM, et al. Optimal asthma control, starting with high doses of inhaled budesonide [correction appears in Eur Respir J 2000;16:579]. Eur Respir J 2000;16:226-35

3 Chowienczyk P, Parkin D, Lawson C, Cochrane G. Do asthmatic patient correctly record home spirometry measurements? BMJ 1994;309:1618.

4 Gibson PG, Coughlan J, Abramson M, Bauman A, Hensley MJ, Walters $\mathrm{EH}$, et al. The effects of self-management education and regular practitioner review in adults with asthma. Cochrane Library. Issue 2. Oxford: Update Software, 1998.

5 Reddel HK, Ware SI, Salome CM, Jenkins CR, Woolcock AJ. Pitfalls in processing electronic spirometric data in asthma. Eur Respir 1998;12:853-8

(Accepted 2 September 2001)
Institute of Respiratory Medicine, Royal Prince Alfred Hospital and University of Sydney,

PO Box M77,

Missenden Road, Camperdown, NSW 2050 Australia

Helen K Reddel research fellow Brett G Toelle research officer Guy B Marks research leader Sandra I Ware research assistant Christine R Jenkins research leader Ann J Woolcock professor

\section{One hundred years ago \\ A chance for a prince-physician}

In an Italian paper, La Tribuna, there recently appeared the following advertisement: "A young lady of noble family, aged 30, of refined education, having an income of 2,000 lire, wishes to get married. The suitor may be broken in fortune, but it is absolutely essential that he should have a loving heart and the title of prince. A medical man preferred." This remarkable advertisement has every appearance of being genuine. The lady lives at Padua, and it may be conjectured that having a limited income and indifferent health, she is looking for deliverance from medical bills in matrimony. To find a husband who could minister to her bodily ailments, and at the same time give her the social advantages of the title of "Princess" might well be the dream of a mature maiden's heart. She is to be commended for her practical common sense in distinctly formulating her conditions before entering on negotiations. The difficulty is to find a man who fulfils them. Princes, indeed, have had little taste for medicine since the days of Henry VIII, who, according to his admirer, Froude, was the best physician in his realm; and Peter the Great of Russia, who was fond of bleeding and bandaging his lieges and extracting their teeth on occasion. There are, we believe, at present in Europe only two princes who are doctors, both of whom belong to the House of Wittelsbach. These are the Duke Karl Theodor of Bavaria, and Prince Ludwig Ferdinand. The former is an ophthalmologist of no mean skill, and only the other day was elected on his professional merits an honorary member of the Belgian Academy of Medicine. They have established on their estates in the Tyrol hospitals of which they themselves are the medical officers. Both these princes, hoever, are married. Our own gracious sovereign, who is a Fellow of both Royal Colleges, is also ineligible for the same reason. We fear, therefore, that the fair maid of Padua will sigh for her prince-physician in vain.

(BMJ 1902;i:164) 